\title{
Theoretical modelling of retention curve for Livet-Gavet loam
}

\author{
Jacques Monnet ${ }^{* 1}$, Luc Boutonnier ${ }^{2}$, Said Tä̈bi $^{3}$, DinoMahmutovic ${ }^{2}$, DenisBranque ${ }^{4}$, \\ ${ }^{1}$ GAIATECH, 22 rue Antoine Chollier, 38170, Seyssinet, France \\ ${ }^{2}$ EGIS, 3, rue Docteur Schweitzer, 38180, Seyssins, France \\ ${ }^{3}$ LOMC, CNRS UMR 6294, Université Le Havre Normandie, BP540, 75058, Le Havre, France \\ ${ }^{2}$ ENTPE, 3 rue Maurice Audin - 69518 Vaulx-en-Velin, France
}

\begin{abstract}
Different approaches have been used for modeling retention curves. The experimental correlation was first proposed [1-3]. The physical modelling of unsaturated soils is used for this study. The shape of the retention curve is a consequence of physical assumptions. The paper presents a theoretical model based on elastic spherical particle arrangement. Firstly, a uniform model is presented with a single diameter of soil particle. The second step extends the use of the model to graded soils. The model uses only physical parameters easy to measure. The model is compared with the experimental retention curve of two different samples, the Livet-Gavet loam $(1.6 \mathrm{~m}-3 \mathrm{~mm})$ as paste and the Gavet sandy loam compacted with 85 falls per layer of Proctor weight. It shows its ability to model the experimental curves. It is of great interest for engineers as it uses only physical parameters. It gives a direct determination of the retention curve along the wetting path and along the drying path. It shows also the importance of adsorbed water to describe the retention curve.
\end{abstract}

\section{Introduction}

The development of numerical calculations and the increase of the power of microcomputers allows to determine the behaviour of large constructions of soil such as dikes, embankments, earthworks. All these earth structures are compacted at the Proctor optimum with a degree of saturation between 80 and $98 \%$ so that the soil is unsaturated. For an accurate estimate of the final soil density state, it is necessary to model soil compaction along a wetting path. In addition, when the construction of the earth structure is completed, it appears drying and wetting events appear associated with rainy and sunny conditions. These events therefore require the development of a model able to simulate the drying and wetting paths to anticipate the future soil deformations.

There are several ways to model retention curves. The first method is to use experimental relationships. It has been successfully initiated (1) by the model of Brooks and Corey [1], which requires the determination of air intake suction and experimental parameter $\delta$; van Genuchten [2] used a new experimental relationship (2) able to simulate larger retention curves with 3 experimental parameters $(\alpha, \mathrm{n}, \mathrm{m})$. Gallipoli et al. [3] followed the same research scheme and proposed a complete experimental relationship (3) with 4 experimental parameters $(\Phi, \Psi, v, \delta)$.

The second method is to consider physical modelling. With this approach, the shape of the retention curve is not chosen in advance, but is a consequence of physical assumptions. A first option is to consider the soil as a porous medium [4-5]. The second option is to consider the soil as a structure consisting of spherical particles. The present study deals with a theoretical model based on the arrangement of elastic spherical particles. This approach allows to explain the physical phenomenon of retention and to calculate with a limited number of physical parameters.

$$
\begin{gathered}
\mathrm{S}_{\mathrm{r}}=\left(\mathrm{s} / \mathrm{s}_{\mathrm{air}}\right)^{-\delta} \\
\mathrm{S}_{\mathrm{r}}=\left[1+(\mathrm{a} . \mathrm{s})^{\mathrm{n}}\right]^{-\mathrm{m}} \\
\mathrm{Sr}=\left\{1 /\left[\left(\Phi .(\mathrm{v}-1)^{\Psi} . \mathrm{s}\right]\right\}^{-\delta}\right.
\end{gathered}
$$

\section{Model of Theoretical retention curve of unsaturated soil}

\subsection{Hypothesis and organization}

Many authors [6-7] mentioned the existence of four saturation zones, each with a distinct behaviour. This hypothesis is taken up in the design of our model, mainly based on the work of Boutonnier [8-9] :

- Domain D1: $\mathrm{s} \geq \mathrm{s}_{\text {air }}$ and $\mathrm{S}_{\mathrm{r}} \leq \mathrm{S}_{\text {rair }}$

The gas phase is continuous into the soil. This state gives a suction greater than the inlet air suction and a degree of saturation lower than the degree of saturation air inlet.

- Domain D2: $\mathrm{s} \leq \mathrm{s}_{\text {air }}$ and $\mathrm{S}_{\mathrm{rair}} \leq \mathrm{S}_{\mathrm{r}} \leq \mathrm{S}_{\mathrm{re}}$ and $\mathrm{u}_{\mathrm{w}} \leq 0$

In this area, the free air disappears. The air is occluded into the ground. The air is in contact with the soil particles. Sucking has the effect of increasing the strength of the interparticle contacts.

- Domain D3: $\mathrm{S}_{\mathrm{re}}<\mathrm{S}_{\mathrm{r}}<1$ and $\mathrm{u}_{\mathrm{w}}>0$

The air is occluded into the soil in the form of bubbles in weak interaction with the skeleton. Capillary tension has no effect on contact forces between soil

*Corresponding author: monnet.jacques @ gaiatech.fr 
particles. D3 corresponds to the case of positive interstitial pressures with a degree of saturation lower than 1.

- Domain D4: $\mathrm{S}_{\mathrm{r}}=1$

There is no air in the gaseous state in the soil. The soil is saturated. The boundary between D3 and D4 can also be expressed by the pore pressure that allows the saturation of the soil by dissolving the air into the water.

In this paper, we consider domains D1 and D2. First, we present the case of a theoretical uniform soil made of spherical balls of a single diameter in the D1 domain. Then the approach is generalized to the case of a granular mixture. The general flow chart for the calculation of the wetting path is shown (Fig.1)

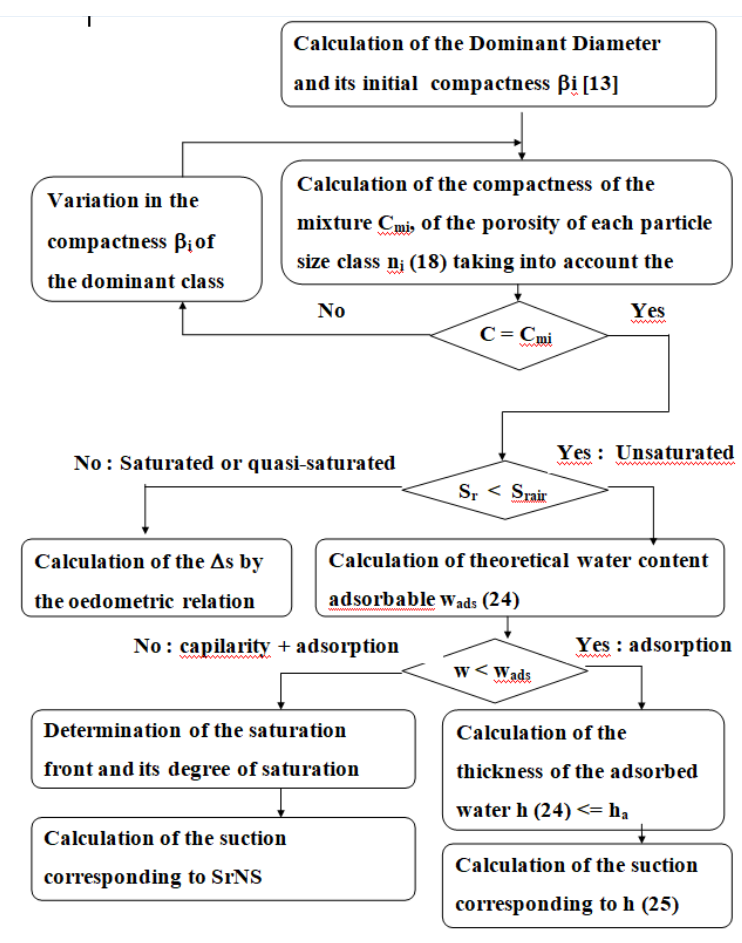

Fig. 1. The organization of the calculation for the wetting path

\subsection{Deformation of spherical particles and meniscus volume: domain D1}

Under the action of water in interparticle contact, there is suction on the cross section of the meniscus and surface tension [10]. The soil model is composed of uniform spherical particles of radius R. According to Laplace's law, the suction is the product of the water surface tension $\mathrm{T}_{\mathrm{c}}$ by the sum of two principal curvatures of radius $\mathrm{r}$ of the meniscus and the radius $\mathrm{b}$ of the corresponding torus. at the wet zone (4). Under the action of a normal force $\mathrm{F}_{\mathrm{N}}(5)$ on the plane of contact, the two balls deform elastically according to the theory [11]. The details of these calculations are in [12].

$$
\begin{array}{r}
s=T_{c} \cdot[1 / r-1 / b] \\
f_{N}=s \cdot \pi \cdot b^{2}+2 \cdot \pi \cdot b \cdot T_{c}
\end{array}
$$

\subsection{Analytical calculation of meniscus volumes with a wetting angle: domain D1}

The contact between the particles and the water has a wetting angle of $\theta_{c}$ which varies in case of drainage or humidification [6]. The meniscus volume calculation for various void ratio was done [12].

\subsection{Arrangement of soil particles for uniform particle size}

For a soil composed of uniform particle size, the void ratio may vary depending on the compaction energy. Monnet et al. [12] show that for the four arrangements, the void ratio is independent of the particle radius, but depends only on the arrangement of the particles. The particle radius influences only the size of the REV (Representative Elemental Volume). The variables that describe the different phenomena on the drying path are the ratio between the air bubble and the particle radius. The Solidworks model allows to determine in the REV:

- the number and the contact angle for each particle,

- the total number of menisci per arrangement.

For the drying path, the model finds:

- the radius of the bubble appearing at nucleation,

- the number of bubbles that can appear in the REV,

- the degree of saturation at nucleation,

- suction at nucleation,

- the radius and the suction of the percolating bubble.

For the wetting path, the model finds:

- the radius of the bubble that percolates,

- the suction at percolation.

The theoretical calculation of the meniscus can only be carried out when menisci are independent. When coalescence occurs, the model assumes that the suction remains unchanged according to [12].

\subsection{Theoretical retention curve for uniform soil: domain D1}

For a uniform soil with the four possible arrangements, the relative position of the particles is known as well as the REV, the void ratio, the number and the orientation of the contacts in the arrangement. On a reverse way, the knowledge of the void ratio allows to know the type of arrangement and the arrangement of the soil particles. The knowledge of the water content or saturation allows to calculate the total volume of water in the REV (6). The knowledge of the number of contacts in the REV and the number of menisci allows to calculate the volume (8) of a single meniscus [12]. The volume of the meniscus depends on the radius of the meniscus, the radius of the particle, and the suction (4). The relationship is corrected for water content to take into account the portion of water bound to the particle surface by adsorption (7). This allows to calculate the volume of the meniscus (8) and the associated suction (4) with a void ratio and with a water content.

$$
\begin{aligned}
& \mathrm{V}_{\mathrm{w}}=\mathrm{S}_{\mathrm{r}} \cdot \mathrm{e} \cdot \mathrm{REV} /(1+\mathrm{e}) \\
& \mathrm{w}_{\mathrm{cap}}=\mathrm{w}_{\mathrm{NS}}-\mathrm{w}_{\mathrm{ads}}
\end{aligned}
$$




$$
\mathrm{V}_{\text {men }}=\mathrm{w}_{\text {cap }} \cdot \mathrm{S}_{\mathrm{r}} \cdot \mathrm{e} \cdot \mathrm{REV} /\left[\mathrm{w}_{\mathrm{NS}} \cdot(1+\mathrm{e}) \cdot \mathrm{Nb}_{\text {meniscus }}\right.
$$

\subsection{Compactness and homogeneity of the granular mixture for an extended granulometry}

The theory of granular mixtures [13] is used here for the natural soil, considering at a first approach that the soil particles are spherical. The theoretical model is organized from the largest to the smallest of $n$ different diameters for soil skeleton particles, such as (9). The symbol $\mathrm{C}$ is the compactness which is equal to the solid volume of the soil sample (10). The relative compactness with respect to the total sample of class $\mathrm{i}$ is noted $\Phi_{\mathrm{i}}$ (11). As a result, the total compactness $\mathrm{C}$ of the soil sample is given by the sum of all the compactness (12). In theory, $\mathrm{R}_{\mathrm{i}}$ corresponds to the volume refusal on the sieve of diameter $D_{i}$, based on the total volume of the grains of the sample (13). Assuming a single density for all aggregates, this term is also the sieve mass refusal based on the total mass of the sample

$$
\begin{gathered}
\mathrm{D}_{1}>\ldots \mathrm{D}_{\mathrm{i}} \ldots>\mathrm{D}_{\mathrm{n}} \\
\mathrm{C}=\mathrm{V}_{\mathrm{s}} / \mathrm{V}_{\mathrm{t}}=1-\mathrm{n} \\
\Phi_{\mathrm{I}}=\mathrm{V}_{\mathrm{si}} / \mathrm{V}_{\mathrm{t}} \\
\mathrm{C}=\Sigma_{\mathrm{j}=1}{ }^{\mathrm{n}} \Phi_{\mathrm{j}} \\
\mathrm{R}_{\mathrm{i}}=\Phi_{\mathrm{i}} /\left(\sum_{\mathrm{j}=1}{ }^{\mathrm{n}} \Phi_{\mathrm{j}}\right)=\Phi_{\mathrm{i}} / \mathrm{C}=\mathrm{M}_{\mathrm{dii}} /\left(\sum_{\mathrm{j}=1}{ }^{\mathrm{n}} \mathrm{M}_{\mathrm{dj}}\right)
\end{gathered}
$$

\subsubsection{Compactness of the dispersed mixture - general case for classified soil}

The theory [13] is adapted to the natural soil by [12] which allows determining the Compactness of the soil mixture $\mathrm{C}_{\mathrm{mi}}$ when the class $\mathrm{i}$ of particle is dominant that is when the class of diameter $i$ fixes the compactness of the mixture.

\subsubsection{Compactness of each class in the mixture: graded soil}

The compactness of the dominant class $C_{i}$ is assumed proportional to $\beta_{i}$ (the compactness of each particle class) and the compactness of the mixture $\mathrm{C}_{\mathrm{mi}}$ when the class $\mathrm{i}$ is dominant. The compactness of the other classes $\mathrm{C}_{\mathrm{j}}$ are calculated by applying the relation (14) between compactness of class and compactness of the mixture in which $C$ is introduced equal to $C_{m i}$ with a known $R_{j}$. Subsequently, an iterative calculation applies a correction to $\mathrm{C}_{\mathrm{mi}}$ (Fig.1) to find a compactness of the mixture (10) identical to the experimental compactness

$$
\mathrm{C}_{\mathrm{j}}=\mathrm{R}_{\mathrm{j}} \cdot \mathrm{C}_{\mathrm{mi}} \cdot / \mathrm{R}_{\mathrm{i}}
$$

\subsubsection{Porosity of each soil class}

Considering a mixture of 3 classes (Fig. 2) of which class 2 is dominant. The volume left free by class 1 is the total volume available for class 2 ; it is given by (15). The volume of void left free by classes 1 and 2 is given by

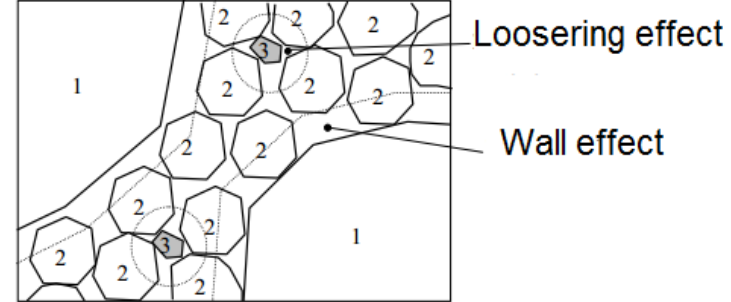

Fig. 2. The perturbations exerted on the middle class grains by the large grains and the small grains [13]

(16), which allows to calculate the porosity of class 2

(17). This relation is generalized for any class i (18)..

$$
\begin{gathered}
\mathrm{V}_{\mathrm{v}} / \mathrm{Vt}=1-\mathrm{V}_{\mathrm{S} 1} / \mathrm{V}_{\mathrm{t}}=1-\Phi_{1}=\mathrm{V}_{\mathrm{t} 2} / \mathrm{V}_{\mathrm{t}} \\
\mathrm{V}_{2} / \mathrm{Vt}=1-\mathrm{V}_{\mathrm{S} 1} / \mathrm{V}_{\mathrm{t}}-\mathrm{V}_{\mathrm{S} 2} / \mathrm{V}_{\mathrm{t}}=1-\Phi_{1}-\Phi_{2} \\
\mathrm{n}_{2}=\mathrm{Vv}_{2} / \mathrm{Vt}_{2}=\left(1-\Phi_{1}-\Phi_{2}\right) /\left(1-\Phi_{1}\right) \\
\mathrm{n}_{\mathrm{i}}=\left(1-\sum_{\mathrm{j}=1}{ }^{\mathrm{i}} \Phi_{\mathrm{j}}\right) /\left(1-\Sigma_{\mathrm{j}=1}{ }^{\mathrm{i}-1} \Phi_{\mathrm{j}}\right)
\end{gathered}
$$

Considering porosity by class of particle, the general relation over the whole sample can be written (19) as a function of the compactness $\mathrm{C}$. We assume the proportionality of value e between the volumes of the class voids $i$ and the compactness of class $i$, which gives (20). One can verified that the sum of all void volumes (21) corresponds to the general theoretical equation (19), which implies the equality of class i void ratio with the sample void ratio (22).

$$
\begin{gathered}
\mathrm{n}=\left(\mathrm{V}_{\mathrm{v}} / \mathrm{V}_{\mathrm{s}}\right) \cdot\left(\mathrm{V}_{\mathrm{s}} / \mathrm{V}_{\mathrm{t}}\right)=\mathrm{e} \cdot \mathrm{C} \\
\mathrm{V}_{\mathrm{vi}} / \mathrm{Vt}=\left(\mathrm{V}_{\mathrm{vi}} / \mathrm{V}_{\mathrm{si}}\right) \cdot\left(\mathrm{V}_{\mathrm{si}} / \mathrm{V}_{\mathrm{t}}\right)=\mathrm{e}_{\mathrm{i}} \cdot \Phi_{\mathrm{i}} \\
\Sigma \mathrm{V}_{\mathrm{vi}} / \mathrm{V}_{\mathrm{t}}=\mathrm{VV}_{2} / \mathrm{Vt}_{2}=\mathrm{n}=\Sigma \mathrm{e}_{\mathrm{i}} \cdot \Phi_{\mathrm{i}} \\
\mathrm{e}_{\mathrm{i}}=\mathrm{e}
\end{gathered}
$$

\subsubsection{Distribution of water content between capillary water and adsorbed water}

For the natural soil, the water is distributed between a capillary water circulating between the grains of soil and an adsorbed water bound to the surface of the grains with no displacement (23). The adsorbed water is distributed uniformly over all the particle of the soil and ensures continuity between the different areas of the capillary.

$$
\mathrm{w}=\mathrm{w}_{\mathrm{cap}}+\mathrm{w}_{\mathrm{ads}}
$$

We assumed :

- considering the particle size distribution it is assumed that the smallest particles saturate before the larger ones - there is a saturation front which separates the small saturated particles from the large unsaturated particles; - all the small diameters situated under the saturation front are saturated with a constant degree of saturation close to 1 , equal to $S_{\text {rair }}$;

- all the larger particles situated above the wetting front participate in the unsaturated behavior $(\mathrm{Sr} \approx 0)$ without capillary suction with a degree of saturation close to 0 ; 
- adsorbed water covers all classes of grains (unsaturated and saturated);

- the suction is related to the water content of the saturation front in the case of a capillary water or to the thickness of the adsorbed water layer in the case of absence of capillary water.

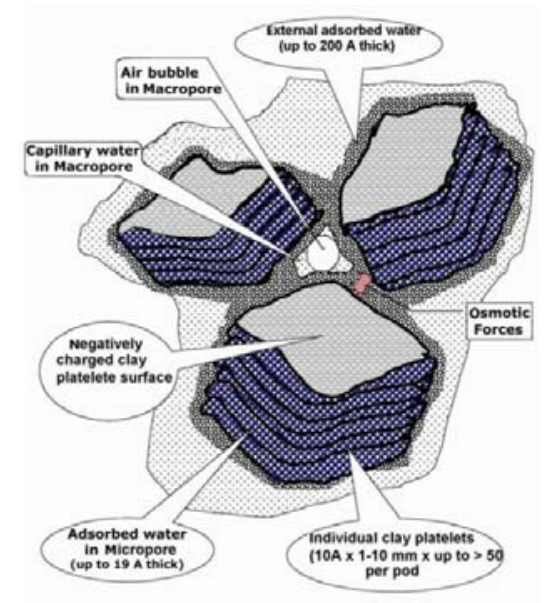

Fig. 3. The Theoretical model of porous space with soil aggregate [14]

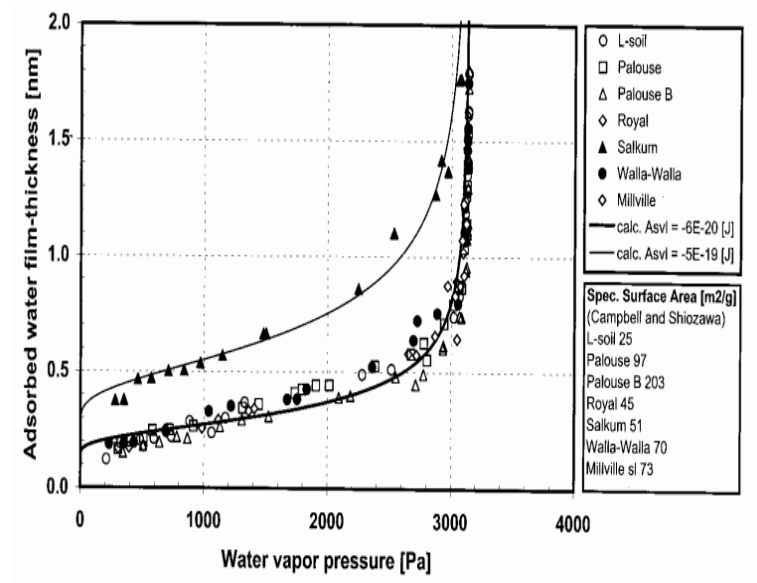

Fig. 4. Thickness of the adsorbed water [4]

\subsubsection{Influence of adsorbed water}

The maximum thickness of the adsorbed water (Fig. 3) is a function of the saturation water vapor pressure according to the experimental expression [4]. It varies between $0.2 \mathrm{~nm}$ and $1 \mathrm{~nm}$ and depends on the nature of the soil and the temperature. The digitization of the two curves (Fig.4) allows to transform the maximum thickness $h_{a}$ of the adsorbed water into an internal variable depending solely on the nature of the soil and the temperature of the water $\theta$. The corresponding water content is then (24), the specific soil surface $S_{a}$ in $\mathrm{m}^{2} / \mathrm{kg}$. Water content is fixed and regulates the capillary water content, following [14] the thickness of the adsorbed water varies under the influence of Van Der. Waals forces and water content which allows to calculate the suction by the expression (25)

$$
\begin{gathered}
\mathrm{w}_{\mathrm{ads}}=\mathrm{S}_{\mathrm{a}} \cdot \mathrm{h}_{\mathrm{a}} \cdot \rho_{\mathrm{w}} \\
\mathrm{s}=\left(10^{-11} / \pi\right) \cdot\left(\mathrm{S}_{\mathrm{a}} / \mathrm{w}_{\mathrm{ads}}\right)^{3}
\end{gathered}
$$

\subsubsection{Degree of saturation of the saturation front}

The capillary water is distributed between a saturated zone of small diameters, a zone of saturation front and a de-saturated zone of large diameters. The saturation front coexists with a layer of adsorbed water of maximum thickness. The water content of the saturation front is obtained by the difference between the total water content, that of the adsorbed water and that of the saturated zone of the soil for the small diameters (7):

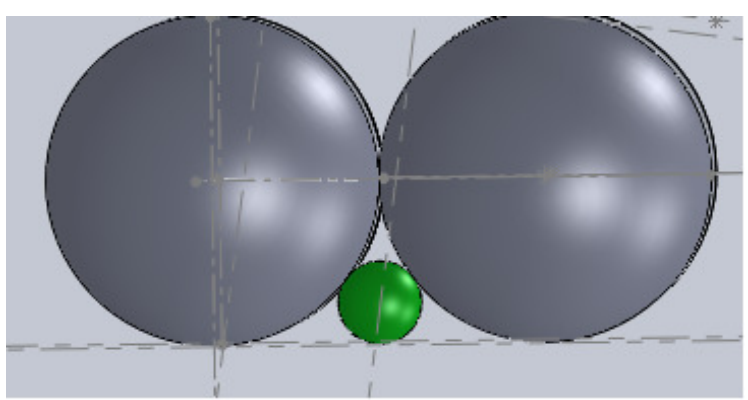

Fig. 5 : Air Bubble (green) in percolation for not connected particles (grey) along the drying path

\subsubsection{Air Inlet Suction and Drainage path}

The model assumes that the air begins to percolate through the soil when the bubble can cross the smallest porosity (Fig.5) corresponding to the dominant class for the air inlet suction $s_{\text {air }}$ and the degree of saturation $S_{\text {rair }}$. Usually the grains of the same class are not joined. Class i grains are considered to laid on a plane of the largest grains forming a wall, and the air bubble must pass through the void between two Class i grains with a ratio of between the radii of the air bubble with respect to grains $i$ of 0.25 . The air inlet suction on a drying path is (26) in the general case where the grains have not joined. Note that the diameter $D_{\text {perco }}$ of the relation (26) corresponds to the minimum porosity of the soil which can be different from the dominant diameter. For a water content lower than the air inlet, the linearity (28) between the suction and the degree of saturation is assumed with the slope $\delta$ (27) which becomes an internal parameter of the model.

$$
\begin{gathered}
\mathrm{s}_{\text {airD }}=\left(16 \cdot \mathrm{T}_{\mathrm{c}}\right) / \mathrm{D}_{\text {perco }} \\
\delta=\log \left(\mathrm{S}_{\text {rair }}\right) / \log \left(\mathrm{s}_{\text {ads }} / \mathrm{s}_{\text {air }}\right) \\
\log \left(\mathrm{s} / \mathrm{s}_{\text {air }}\right)=-\log \left(\mathrm{S}_{\mathrm{r}}\right) / \delta
\end{gathered}
$$

\subsubsection{Determination of the specific surface of the natural soil}

The method developed by [15] is used to determine the specific surface area $S_{a}$ of the soil using (27) with the Avogadro $A_{v}$ number and $A_{M B}\left(130 \AA^{2}\right)$ the area covered by a molecule of methylene blue and $\mathrm{M}_{\mathrm{MB}}$ the molar 
Table 1. Parameters used for the calculation

\begin{tabular}{|c|c|c|c|c|c|c|c|c|c|c|c|c|}
\hline & $\mathbf{e}$ & $\mathbf{w}_{\mathbf{r}}$ & $\begin{array}{c}\boldsymbol{\gamma}_{\mathbf{s}} \\
\mathbf{k N / \mathbf { m } ^ { \mathbf { 3 } }}\end{array}$ & $\begin{array}{c}\mathbf{E}_{\mathbf{p}} \\
\mathbf{G P a}\end{array}$ & $\mathbf{v}_{\mathbf{p}}$ & $\begin{array}{c}\boldsymbol{\theta}_{\mathbf{c}} \\
\mathbf{D e g}\end{array}$ & $\begin{array}{c}\mathbf{T}_{\mathbf{c}} \\
\mathbf{k N} / \mathbf{m}^{\mathbf{2}}\end{array}$ & $\begin{array}{c}\boldsymbol{\theta} \\
\mathbf{D e g} .\end{array}$ & $\begin{array}{c}\mathbf{V B S} \\
\mathbf{c m}^{\mathbf{3}} / \mathbf{1 0 0 g}\end{array}$ & $\mathbf{S}_{\text {rair }}$ & $\mathbf{C}_{\mathbf{c}}$ & $\mathbf{C}_{\mathbf{s}}$ \\
\hline Drying & 0.424 & $0.17 \mathrm{~d}$ & 27.2 & 107 & 0.2 & 0 & 7.28 & 20 & 0.18 & 0.954 & 0.1 & 0.015 \\
\hline Wetting & 0.375 & $0.13 \mathrm{w}$ & 27.2 & 107 & 0.2 & 5 & 7.28 & 20 & 0.18 & 0.954 & 0.1 & 0.015 \\
\hline
\end{tabular}

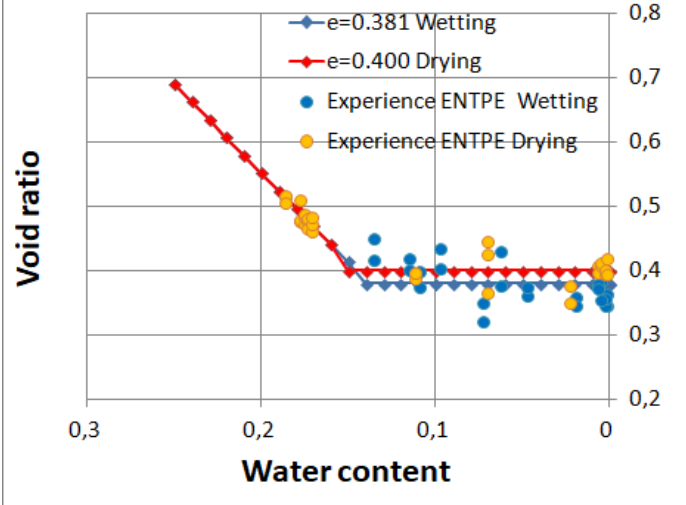

Fig. 5. Variation of the void ratio along water content

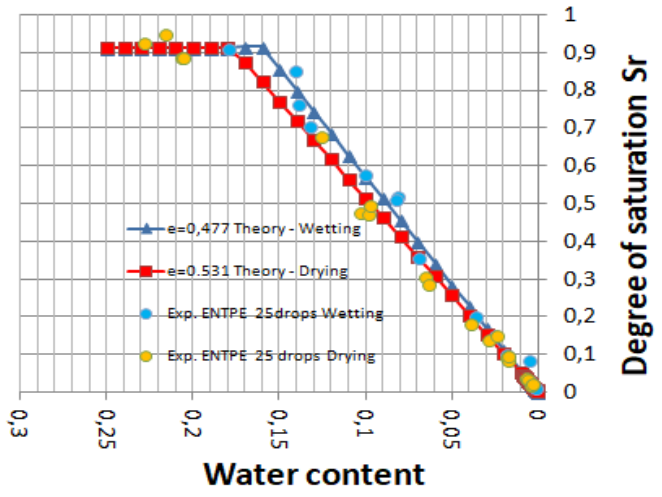

Fig. 7. Degree of saturation along water content

weight of the methylene blue equal to $319.87 \mathrm{~g}$. In this theory, the total mass of adsorbed $\mathrm{M}_{\mathrm{B}}$ is known by the value of VBS. The total number of $M_{B}$ molecules is known thanks to Avogadro Av's molar weight and number. By multiplying the unit area of a methylene blue AMB molecule, it is possible to determine the specific surface area $S_{a}$ covered by a layer of $M B$ molecules. The relation (29) is valid for the domains D1 to D4. The theoretical soil model also calculates the total grain area per unit mass based on the four arrangements with (30). The different particle surface per unit volume are indicated for particles of $2 \mu \mathrm{m}$ radius by [16] It should be noted that this theoretical specific surface area $\mathrm{S}_{\mathrm{s}}$ is always smaller than the experimental one $\mathrm{S}_{\mathrm{a}}$. This is supposed to reflect the actual shape of the particles which are not spherical, but elongated, flattened or of any shape. The shape coefficient $\varphi_{\mathrm{a}}$ is the ratio between $\mathrm{S}_{\mathrm{a}} / \mathrm{S}_{\mathrm{s}}$ and can be determined with the dry density of the soil $\rho_{d}$, the theoretical surface of the rank $i$ of the particle $S_{\text {sVERi }}$, the dry density $\rho_{d i}$ of the class $i$ of the particle $d_{i}$ and the refusal $R_{s i}$ of the sieve of rank $i$. This coefficient is defined before the calculation of the retention and constitutes an internal variable of the model.

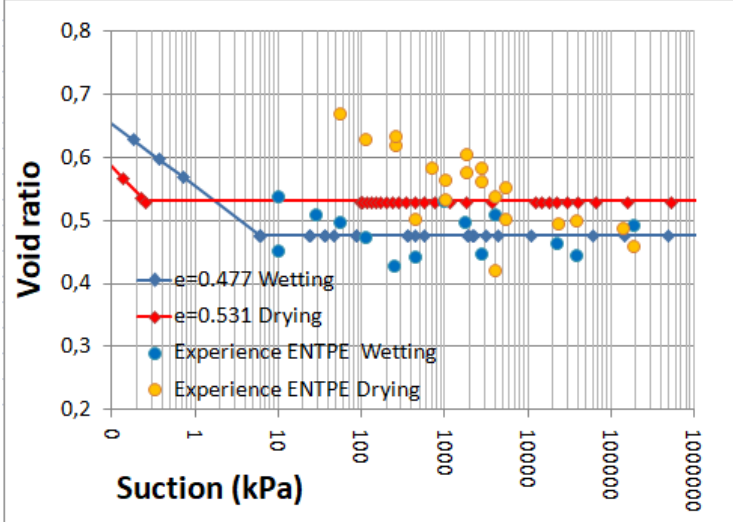

Fig. 6. Retention curve for drying and wetting path

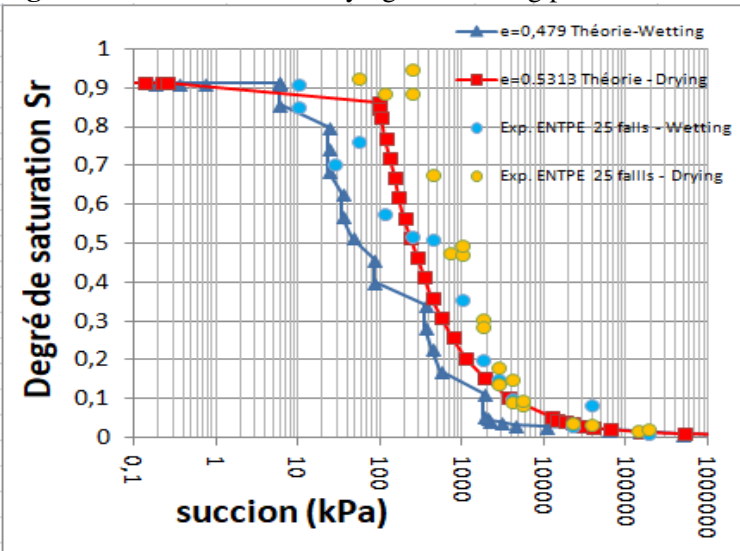

Fig. 8. Retention curve for drying and wetting path

$$
\begin{gathered}
\mathrm{S}_{\mathrm{a}}=0.01 . \text { VBS. } \mathrm{A}_{\mathrm{v}} \cdot \mathrm{A}_{\mathrm{MB}} / \mathrm{M}_{\mathrm{MB}} \\
\mathrm{S}_{\mathrm{s}}=\sum_{\mathrm{i}=0}{ }^{\mathrm{n}} \mathrm{S}_{\mathrm{si}} \cdot \mathrm{R}_{\mathrm{si}} / \rho_{\mathrm{di}}
\end{gathered}
$$

\section{Compacted Livet-Gavet loam}

The soil was taken from the site of the Livet-Gavet EDF plant [17]. The granulometric curve of the natural soil has a $D_{\max }$ of $80 \mathrm{~mm}$ and a Dmin of $1 \mu \mathrm{m}$. The lower part of the curve, less than $0.2 \mathrm{~mm}$, was analyzed by sedimentometry. For calculation the silty sand is suppressed over $2 \mathrm{~mm}$ according to the experimental procedure. A sieve at $80 \mu \mathrm{m}$ of $31 \%$ and a VBS of 0.18 are measured. This soil is classified A1 as a low plastic loam with a maximum adsorbed water thickness of $0.44 \mathrm{~nm}$ at $20^{\circ}$. The suction measurements are carried out under atmospheric pressure without axis translation, so that the properties of water gaz and dissolution of air into the water are not changed from the field.

The theoretical specific surface of the grains of the mixture, calculated by the relation (30) gives a specific surface area of $690 \mathrm{~m}^{2} / \mathrm{kg}$ for a void ratio of 0.7 , whereas the relation (30) for the VBS index of $0.18 \mathrm{~cm}^{3} / 100 \mathrm{~g}$

Corresponding author: monnet.jacques @ gaiatech.fr 
leads at a specific surface of $4405 \mathrm{~m}^{2} / \mathrm{kg}$. The form coefficient $\varphi_{\mathrm{a}}$ is then 0.156 .

The sample was dried in the oven for 24 hours and then re-moistened to compact at different moisture levels until the water content of the Proctor optimum was reached. The silt is compacted under 85 shots per layer of Proctor's weight, with a water content of $10.9 \%$ and a void ratio of 0.42 . This method of compaction was chosen to highlight the effect of compaction on the soil structure and the retention curve. The various graphs presented show the void ratio and the moisture content (Fig. 5), the void ratio and suction (Fig.6). the degree of saturation and water content (Fig.7), the degree of saturation at suction (Fig.8)

Along the unsaturated behaviour, a good correspondence is found between the model results and the humidification path experiment, a good estimate of the air inlet suction, and a slight underestimation of the suction. For wetting the behaviour is well identified with adsorbed water alone for suctions greater than $4000 \mathrm{kPa}$ with a reversible response to drainage and humidification.

\section{Conclusions}

A model has been developed to represent the behaviour of unsaturated soil in its phase of water retention on a drying path, but also on a wetting path. The model uses a non uniform particle size distribution and takes into account the degree of compaction of the different grain size classes. The model explains the retention behaviour along wetting by the development of menisci between particles and along drying by the percolation of air bubbles through the smallest porosity of the soil. The two paths meet when there is no more capillary water and only the adsorbed water remains. It uses only geotechnical parameters accessible by routine laboratory experiments and will be developed for other types of soils. It allowed to find the main behaviours of the soil, that it is the evolution of the void ratio, the water content, the degree of saturation according to the suction, but also the suction of air inlet for a compacted loam beyond the OPN ( 85 falls / layer). It allowed to show the importance of the water adsorbed in the phenomenon of retention. The authors thank the ANR Terre Durable project for its financial support.

\section{References}

1. R.H. Brooks, A.T. Corey, Proceedings of the American Society of Civil Engineers 2, 61-88 (1966)

2. T.V. Genuchten, Soil Science Society 44, 892-898 (1980).

3. D. Gallipoli, S.J. Wheeler, M. Karstunen, Géotechnique 53, 105-112 (2003).

4. D. Or, M. Tuller, Water Resources Research 35, 3591-3605 (1999).

5. K. Kutilek, M. Nielsen, K. Reichardt, 2007. Soil Water Retention Curve, Interpretation, in:
International Centre for Theoretical Physics. Presented at the ICTP, Trieste (2007).

6. J.-P. Gras, Approche micromécanique de la capillarité dans les milieux granulaires: rétention d'eau et comportement mécanique. Thèse, Université de Montpellier 2, Montpellier (2011).

7. S. Salager, Etude de la rétention d'eau et de la consolidation des sols dans un cadre thermo-hydromécanique. Thèse, Université Montpellier 2, Montpellier (2007).

8. L. Boutonnier, Comportement hydromécanique des sols fins proches de la saturation. Cas des ouvrages en terre : coefficient $\mathrm{B}$, déformations instantanées et différées, retrait / gonflement. Thèse INPG Grenoble (2007)

9. L. Boutonnier L., M. Bufalo, T. Dubreucq., J.J. Fry, J.M. Lejeune, D. Mahmutovic (2019). Conception et construction des ouvrages en sols fins. Sous la coordination de L. Boutonnier. 512 pages. Presses des Ponts (ISBN : 9782859785222)

10. S. Taïbi, Comportement mécanique et hydraulique des sols soumis à une pression interstitielle négative - Etude expérimentale et modélisation. Thèse, Ecole Centrale de Paris, Paris (1994).

11. H. Hertz, 1881. Über die Berührung fester elastischer Körper. Journal für die reine und angewandte Mathematik 92, 156-171.

12. J. Monnet, D. Mahmutovic, L. Boutonnier, S. Taibi, European Journal of Env. and Civil Eng., 23, 3, 345367 (2019)

13. F. De Larrard, Structures granulaires et formulation des bétons, Etudes et Recherches des Laboratoires des Ponts et Chaussées. Laboratoire central des Ponts et Chaussées (1999).

14. S. Frydman, R. Baker, International Journal of Geomechanics 250-257 (2009).

15. J.C. Santamarina, K.A. Klein, Y.H. Wang, E. Prencke, Canadian Geotechnical Journal 39, 233241 (2002).

16. J. Monnet, D. Mahmutovic, L. Boutonnier, S. Taibi, R. Andrianatrehina, D. Branque, N.L. Hoang, European Journal of Env. and Civil Eng. 23, 7, p.831-865 (2017)

17. Hoang, N.L., Etudes des propriétés hydromécaniques d'un sable limoneux: de la saturation partielle à la saturation complète. Thèse Ecole Nationale des Travaux Publics de l'Etat (2017). 